\title{
An Empirical Study of the Influence of Continuing Education on Youth Entrepreneurship in Taiwan
}

\author{
Chang-Qing Liu ${ }^{1}$, Jeffrey Hugh Gamble ${ }^{2}$, I Hua Chen $^{3}$ \\ 1. Panyapiwat Institute of Management, Nonthaburi, Thailand \\ 2. National Chiayi University, Taiwan \\ 3. Qufu Normal University, Shandong, China
}

\begin{abstract}
Despite the importance of lifelong education and its reported benefits for graduates entering the workforce, few empirical studies have evaluated the relationship between continuing education on entrepreneurship. In order to address this research gap, this study conducted secondary data analysis from the 2015 Adult Education Survey in Taiwan (AEST 2015) conducted by the Taiwan Ministry of Education. The purpose of this study was to determine the proportion of youth engaged in entrepreneurship (as measured by self-employment) and evaluate the relationship between continuing education and youth entrepreneurship. A sample from Taiwan was purposefully selected due to cultural factors which balance Eastern and Western approaches to education, allowing for better generalizability to a variety of populations. Data from a total of 2,696 valid participants was utilized. The results are as follows: a) the rate of youth entrepreneurship in Taiwan is moderate, at $8 \%$; b) participation in continuing education demonstrated no significant relationship on youth entrepreneurship; c) entrepreneurial youth tend not to participate in continuing education, citing reasons including "lack of time" and "lack of necessary courses" at a frequency higher than nonentrepreneurial youth; and d) in terms of opportunities for future participation in continuing education, entrepreneurial youth placed less emphasis on the importance of transportation costs and tuition fees as compared to non-entrepreneurial youths. The results of this study suggest that continuing education courses are not currently meeting the
\end{abstract}


needs of young entrepreneurs. Conclusions and suggestions are provided in terms of the evaluation of youth self-employment and continuing education opportunities for the promotion of entrepreneurship.

Best Evid Chin Edu 2019; 3(2):331-346.

Doi: 10.15354/bece.19.ar1261.

Keywords: Taiwan Youth; Self-employment; Entrepreneurship; Continuing Education

Correspondence to: Jeffrey Hugh Gamble, Department of Foreign Languages, National Chiayi University. Taiwan. E-mail: gamble@mail.ncyu.edu.tw.

About the Author: Chang-Qing Liu, Panyapiwat Institute of Management, Nonthaburi, Thailand. E-mail: Lcqing619@foxmail.com.

I Hua Chen, Chinese Academy of Education Big Data, Qufu Normal University, Shandong, China. E-mail: aholechen@gmail.com.

Funding: Jining Social Science Research Project (Project No. 19JSGX018).

Conflict of Interests: None. 


\section{Introduction}

$\mathrm{S}$ ELF-employment ideally allows theoretical knowledge to be applied directly to gain advantages in the employment market, including increased savings, wealth creation, and social mobility (Quadrini, 1999). Greater attention is being paid to the cultivation of practical and applied skills to meet the demands of industry, leading to a boom in research related to self-employment in recent years (Jia, et al., 2018). In terms of youth entrepreneurial, early advances in universities near Silicon Valley (Bates \& Bates, 1997) began to establish links between the pragmatic demands of society and industry and university course content, overturning traditional theory- of higher education while simultaneously prompting an upsurge in youth entrepreneurship education around the world. In China, for example, "Popular innovation, entrepreneurship" has become a central educational policy aimed at promoting China's economic transformation, upgrading and improving the quality and efficiency of teaching and learning, and promoting the development of an innovative and competitive nation (State Council of the People's Republic of China, 2015). In fact, it is considered a fundamental social goal of developed and developing nations to foster the value-creation and "job making" potentials of youth through entrepreneurship initiatives (Arend, 2019).

Many scholars have begun to scrutinize the issue of youth entrepreneurship, focusing on how institutes of education can provide suitable curricula to meet the needs of students for fostering entrepreneurship at both the secondary and post-secondary levels. In terms of courses provided to high school students, some research has found an improvement in students' perceptions of the feasibility of entrepreneurial endeavors, but no change in their intention to seek self-employment, with extra-curricular entrepreneurial experiences and students' propensity towards entrepreneurship more predictive of entrepreneurial intention (Cardoso, et al., 2018). In terms of college students' entrepreneurship, Bao et al. (2018) urge universities to strengthen courses emphasizing innovation and creativity while providing relevant practical training activities. A recent study of Nigerian college students analyzed their feelings regarding entrepreneurship education courses offered by the university, reporting a positive impact on selfemployment and recommending that universities provide opportunities for students to interact with industry partners and engage in small-scale projects or business ventures (Afolabi, et al., 2017).

As a post-secondary education is increasing valued by youth seeking employment, college education and youth entrepreneurship should be closely linked. Nevertheless, although universities provide systematic and well-designed courses intended to have a direct effect on youth entrepreneurship, the role of continuing education must be evaluated. That is, the relationship between continuing education opportunities offered to youth after graduation and youth entrepreneurship should be evaluated. Due to the lack of continuing education institutes emphasizing entrepreneurship, developing related curricula is a critical issue, particularly given the strong link between academic institutions and economic development (Chowdhury, et al., 2019). 
Research on entrepreneurship education at the university level noted that youth entrepreneurship could not solely rely on cultivation through curricula, but must take advantage of resources outside of the university (Afolabi et al., 2017). In fact, continuing education is seen as pivotal in enhancing the "start-up" and "human capital" aspects of entrepreneurship (Ács, et al., 2018). In fact, according to Lim, et al. (2019, p. 74) continuing education must include instructional factors that can "(a) effectively deliver learning content, (b) model ways of being, (c) cultivate ways of thinking, (d) facilitate self-efficacy, and (e) contribute to forming a better society." Part of this involves experiential and hands-on learning, thus meeting the criteria of scholars who promote increased use of projects and links to industry partners (Afolabi, et al., 2017; Bao, et al., 2018; Cardoso, et al., 2018).

In sum, current studies on entrepreneurship education have largely concentrated on formal higher education environments, neglecting the potentially powerful role of continuing education in promoting youth entrepreneurship. The few studies on continuing education and entrepreneurship (Liberto, 2005; Wada \& Muhammad, 2010) have failed to empirically evaluate the relationship between continuing education and youth entrepreneurship. To bridge this literature gap, this study used data from the 2015 “Adult Education Survey in Taiwan" (AEST 2015) released by Taiwan's Ministry of Education (2018) and conducted secondary analysis.

The rationale for using data from Taiwan is due its unique blend of western and eastern cultures (Sun \& Huang, 2018) leading to what Yang (2019, p. 15) refers to as "a mix of globalization, internationalization, religion, historic legacy, national policy, and local knowledge." The difference between Eastern and Western environments has also been discussed in relation to youth entrepreneurship (Wang \& Millington, 2011), finding that Chinese students were more strongly influenced by work experience, while Americans considered family background factors more seriously. Taiwan, on one hand, is deeply influenced by western culture (especially the United States), but also embraces Chinese traditional culture. Thus, this study uniquely seeks to use data from Taiwan to test the relationship between continuing education and youth education from a perspective where both Eastern and Western principles are valued, thus allowing us to cautiously generalize these results in order to provide suggestions and contributions for researchers and practitioners internationally. Based on data selected from the AEST 2015 that investigates the participation of young people in continuing education and the nature of their current employment, we can clarify how continuing education should be planned so as to have a positive effect on youth entrepreneurship. The four research questions of this study are:

- What is the frequency of entrepreneurship (self-employment) among youth?

- What is the frequency of participation in continuing education among youth?

- Does continuing education influence the entrepreneurial behaviors of youth?

- What differences exist between entrepreneurial and non-entrepreneurial youth in terms of reasons for and against enrolling in continuing education?

\section{Literature Review}


In recent years, there is a growing emphasis on the importance of self-employment. In terms of the influence of self-employment in individuals, research highlights both the benefits, such as potential mental and physical health benefits (Nikolova, 2019) and autonomy and work-life balance (Ortlieb, et al., 2017), as well as the drawbacks, such as stress and insomnia (Kollmann, et al., 2019) and relative insecurity and instability (Nazio \& Gábos, 2017). Within the context of self-employment, international scholars have paid increasing attention to youth entrepreneurship, in particular. However, most studies discuss the incentive policies of local governments (eg., Rapp, et al., 2018) and policy support for innovation and entrepreneurship curriculum design by universities (Liu, 2018).

\section{Research on Youth Entrepreneurship in Taiwan}

While the government in Taiwan has proposed policies to encourage youth entrepreneurship (Ministry of Education, 2009), few studies have been conducted related to entrepreneurship. Most studies related to youth entrepreneurship have evaluated university environmental or policy factors unrelated to continuing education (eg., Yu, et al., 2017). One empirical study found in the literature was by Chen et al., (2015) who found no significant improvement in entrepreneurial intention after offering lectures by entrepreneurial industry experts, stating that hands-on experiences are more influential, while other traditional formal educational approaches add little to the promotion of youth entrepreneurship. Another study compared Taiwanese and Hong Kong university students, emphasizing the role of personality (Hsu \& Wang, 2019), which is certainly a potential factor, but does not provide any recommendations for educational approaches for fostering youth entrepreneurship. Another paper offered general policy recommendations, without evaluating empirical data (Feng, 2016).

Most scholars, in fact, have explored the issue of youth employment from a broader perspective, largely emphasizing factors predicting youth employment instead of focusing on entrepreneurship. For example, Ding and Yan (2011) examined potential relevant factors influencing college students' employment, investigating the mediating effect of self-cognition and interpersonal relationships. From an even broader perspective, Liu and Lin (2011) explored the relationship among individual-level factors, learning outcomes, and graduation trends for different types of college students.

\section{Research on Continuing Education in Taiwan}

In addition to the lack of studies on youth entrepreneurship, very few studies related to continuing education in Taiwan have been published, apart from some which relate to adult education that target older segments of the population. Among the few examples in the literature with relevance to continuing education for youth are papers focused on the need for innovation ( $\mathrm{Lu}$, et al., 2016) and learner loyalty (Wang \& Hsu, 2016) to enhance the competitiveness of continuing educational institutes. While innovative practices for enhancing youth entrepreneurship and attracting and retaining students in continuing education programs are important issues, the literature from Taiwan is lack- 
ing in providing any suggestions related to entrepreneurship of any kind. Likewise, while other studies have been conducted with institutions for continuing education, the focus has been overwhelmingly on the health profession, such as nursing, which is not an appropriate avenue for self-employment.

Thus, some recommendations for continuing education must be found from the international literature. However, here too the literature is scant. Of the few papers found relevant to youth entrepreneurship in the context of continuing education are the following examples. In the context of non-formal education, overall, Pantea (2015) suggests that curricula should emphasize raising awareness of the social challenges facing young entrepreneurs. Bhat and Khan (2014) found that, while not currently being successfully executed, continuing education for entrepreneurship should provide research-based and needs-based instruction with more available courses. Karimi, et al. (2010) reiterate the general recommendations most commonly cited in the literature, such as the need for clear policy, industry-academic collaboration, embeddedness across the school curricula, and the use of hands-on projects to foster youth entrepreneurship.

\section{Evaluating the Relationship between Continuing Education and Youth Entrepreneurship}

As the concept of lifelong learning becomes more prevalent, continuing education is has become more important and valued. In particular, Technical and Vocation Education (TVE) in Taiwan has received a great deal attention from policy-makers, and funding for continuing education for TVE has been increased, with the Ministry of Education [MOE] (2010, p. 42) noting that "occupational continuing education must be more strongly promoted, and designed with a key focus on flexibility and practicality." As such, the MOE advocates for developing creative thinking, increasing entrepreneurshiprelated courses, skill-based instruction, rewards for entrepreneurial performance, and offering business planning and counseling services (MOE, 2010). Thus, compared to school-based entrepreneurial courses emphasizing theory and lacking in practical skills training, continuing education should emphasize the synergy of knowledge and practice (Jin, 2008). Logically, continuing education should be associated with youth entrepreneurship by instilling key competences required for youth entrepreneurship, and the motivation to pursue self-employment opportunities. Demonstrating this close relationship between continuing education and youth entrepreneurship, Liao (2013) pointed out that both the Taiwan and the Japanese governments provide courses specifically for young entrepreneurs.

Although a positive relationship between continuing education and youth entrepreneurship is expected, some specific questions must be explored. For example, the lack of relevant empirical evidence related to the role continuing education in developing youth entrepreneurship, and data on which continuing education pipelines are most effective. The evaluation of specific factors related to continuing education, such as tuition, class time, and course content, have yet to be clearly evaluated based on empirical data in terms of their contribution to youth entrepreneurship. As such, this study 
uses responses from youth, aged 18 to 35 , in relation to their entrepreneurship (evaluated by self-employment) and their participation in and perspectives towards continuing education.

\section{Research Method}

This study adopted data from the AEST 2015 survey in order to conduct secondary analysis. This section describes the data source, the background of subjects, and the corresponding data which was analyzed.

\section{Data Source and the Background of Subjects}

Since 2009, the Ministry of Education (MOE) of Taiwan has conducted a nationwide large-scale adult education survey every three years, entitled "Adult Education Survey in Taiwan". The last survey was conducted in 2015 and released by the MOE in 2018 (Ministry of Education [MOE], 2018). The result of the survey released by the MOE serves as the source of the data used in this study. In the AEST 2015 survey, the population included adult over the age of 18 who were not currently enrolled in a formal educational institute (while students in continuing educational institutions were included). The survey was conducted through telephone interviews which asked respondents to answer all items from a questionnaire. Random sampling was carried out based on an established electronic database of telephone numbers from each town and urban area in Taiwan. The telephone interview was conducted with a random digital dialing (RDD) method for computer-assisted telephone interviewing (CATI). The data were evaluated for outliers, which were then removed systematically. At a confidence level of $95 \%$, the sampling error was estimated at $\pm 0.93 \%$ overall and between $\pm 3.00 \%$ and $\pm 5.66 \%$ for each county surveyed (MOE, 2018). Expert validity for the instrument was established a) through consultation meetings with experts before the questionnaire was finalized and $b$ ) the use of the questionnaire on four separate occasions. The representativeness of the questionnaire results in terms of location and gender were established through Chisquared tests.

From the entire dataset of 11,000 participants, a sample of 2,696 youth between the ages of 18 and 35 was selected (1,249 males and 1,447 females; 1,412 unmarried and 1,284 married) for analysis.

\section{Measurement}

Among the variables evaluated by the AEST 2015, respondents were asked about their current work and participation in continuing education during their past year. For the purposes of this study, we have selected the following four relevant aspects for secondary analysis.

\section{Work in the Past Year}


According to the data from AEST 2015, we further classified respondents into two categories: "self-employed" and "employed by others" according to Question 7 of the demographic section posed to participants, which reads "What was your employment situation last year?" with options of "employer," "privately hired," civil servant," "unpaid family work," and "self-employed," in addition to "unemployed."

\section{Involvement in Continuing Education}

The demographic section of the AEST 2015 also asks respondents regarding their participation in continuing education during over the past year. Question 8 asks students "Which of the following type educational organization do you belong to?" With a total of 18 possible items including various forms of continuing education (e.g. study courses organized by government or private organizations) in addition to options including various types of universities. If respondents indicated that they have participated in continuing education, a code of 1 was used for the data set. For respondents who did not participate in continuing education, a code of 2 was used.

\section{Reasons for Not Participating in Continuing Education}

In the "adult education" section of the AEST 2015 survey, Question 23 asks respondents "What is the most important reason why you did not participate in learning activities last year?" Reasons for not participating in any continuing education include "economic considerations," "lack of time," and "traffic inconvenience" and are listed in full in Table 3 below. Participants were restricted to the selection of one choice which was considered most important to them.

\section{Reasons for Willingness to Participate in Continuing Education in the Fu- ture}

In view of whether the participants will participate in continuing education in the future, the "adult education" section of the AEST 2015 includes question 26, "If you have the opportunity to participate in education in the future, how important are the following factors? Responses to five-point Likert-type responses ranging from very important to very unimportant, including eight items, such as class time, tuition fees, and location, which are listed in full in Table 4 below.

\section{Data Analysis}

For the first research question regarding the frequency of entrepreneurship (selfemployment) among youth the proportion of young entrepreneurs in Taiwan, and the second research question regarding the frequency of youth participating in continuing education, relevant data were first evaluation by descriptive statistics, including the percentage of youth reporting self-employment. Then, z-tests were used to test whether the difference between the proportion of entrepreneurs and non-entrepreneurs was statistically significant, as well as to compare the results of entrepreneurship and continuing education reported in the literature. A $\mathrm{z}$ test was the suitable analysis for determining 
whether a difference in observed counts is significantly different from the expected proportion.

For the third research question, evaluating the relationship between continuing education and youth entrepreneurship, we first conducted a Chi-squared analysis to evaluate the correspondence between involvement in continuing education and entrepreneurship.

To answer the fourth research question, two approaches were needed. Since responses regarding reasons for not enrolling in continuing education utilized count data (single option), Chi-squared analysis was used to determine the significance of adjusted residuals, in order to determine the significance of differences between entrepreneurial and non-entrepreneurial youth. The data for reasons related to being willing to participate in continuing education in the future was based on Likert-type responses. As such, we used independent t-tests to evaluate the significance of the difference between the two groups in terms of the importance placed on each item.

\section{Results}

\section{The Proportion of Entrepreneurship in Taiwan Youth}

Descriptive statistics show that from the 2,696 youth aged 18 to 35 years that were surveyed, only 234 (8\%) were classified as entrepreneurs, with the remaining 2,459 (94\%) classified as non-entrepreneurial. The results of the z-test demonstrate that the proportion of entrepreneurs differed significantly from random chance, or a proportion of .5 , $(\mathrm{z}=-42.91, \mathrm{p}<0.01)$, with the number entrepreneurial youth significantly lower than non-entrepreneurial youth. A more reasonable comparison, based on a report by International Labour Office (2017), would be the estimated global self-employment rates of $6.8 \%$ for upper-middle income countries and $23 \%$ for low-income countries. Using these proportions, Taiwan's youth entrepreneurship is actually higher than the average rate for upper-middle income countries $(\mathrm{z}=3.87, \mathrm{p}<0.01)$, while lower than the average rate for lower-income countries $(\mathrm{z}=-17.67, \mathrm{p}<0.01)$. When compared to the youth selfemployment rate in mainland China of around $15 \%$, estimated by calculating employment and self-employment values from the report by Wang, Bao, Cao, and Kring (2016), Taiwanese youth have a relatively lower level of self-employment $(z=-9.19, p$ $<0.01$ ). As compared to Japan, with an overall self-employment rate of $4.6 \%$ (Niiyama, et al., 2018), Taiwanese youth demonstrated greater entrepreneurship $(\mathrm{z}=10.11$, $\mathrm{p}<0.01)$.

\section{The Proportion of Youth Participating in Continuing Educa- tion}

Descriptive statistics show that from the 2,696 youth aged 18 to 35 years that were surveyed, 889 (33\%) enrolled in continuing education, with the remaining 1,804 (67\%) not taking any form of continuing education. The results of the z-test demonstrate that proportion of students enrolled or not enrolled in continuing education differed significant- 
ly from random chance, or a proportion of $.5,(\mathrm{z}=-17.68, \mathrm{p}<0.01)$, with the number of youth in continuing education significantly lower than those who were not. A more reasonable comparison, based on a report by Organization for Economic Co-operation and Development (2010), would be the average continuing education enrollment rate for OECD countries of $40 \%$. Using these proportions, Taiwan's continuing education enrollment rate is lower than the average rate for OECD countries $(z=-7.45, p<0.01)$, and lower than the averages of other Asian countries, such as Japan (42\%) and Korea $(50 \%)$, as reported in (OECD, 2018).

\section{The Relationship between Continuing Education and the En- trepreneurship of Taiwanese Youth}

In order to address the third research question, Chi-squared analysis was conducted (see Table 1), with the results showing that the enrollment in continuing education did not affect entrepreneurship $\left(\chi^{2}=0.07, \mathrm{p}=0.80\right)$.

\section{The Importance of Factors Influencing Youth Future En- rollment in Continuing Education}

To answer the fourth research question, we first examined differences in terms of the reasons for not participating in continuing education between entrepreneurial and nonentrepreneurial youth. The overall Chi-square test results demonstrated that there were differences within the cross column table $\left(\chi^{2}=26.61, p=0.01\right)$ (see Table 2). Since adjusted standardized residuals match the t-distribution, adjusted residuals greater than an absolute value of 1.96 are significant at $p<0.05$. The items for "lack of time" and "not providing the required course" met this criterion.

Finally, regarding factors influencing willingness to enroll in continuing education in the future, independent t-test results show that the two groups only have significant differences in terms of "tuition fees" and "transportation costs" (see Table 3). These items were perceived as less important by entrepreneurial respondents as compared to non-entrepreneurial respondents: tuition fees $(t=3.29, p=0.01, d=0.24)$ and transportation $(t=2.76, p=0.04, d=0.20)$. It should also be noted that course content, while not significantly different for the two groups, "course content" was deemed the most important factor, along with class time and location.

\section{Discussion}

Considering the importance of lifelong learning, continuing education has been advocated and promoted globally (Karimi et al., 2010). However, despite the global upsurge of youth entrepreneurship (Jia et al., 2018), most studies focus on traditional college education with no studies empirically evaluating the role of continuing education. In order to bridge this gap, this study conducted secondary analysis of Taiwan's AEST 2015 data set, since Taiwan is considered to represent elements of both Eastern and Western cultures (Sun \& Huang, 2018; Yang, 2019), and thus can serve as a valuable 


\begin{tabular}{|c|c|c|c|}
\hline & & Enrolled & Not Enrolled \\
\hline \multirow{2}{*}{ Entrepreneurs } & $n$ & 79 & 155 \\
\hline & $\%$ & $33.8 \%$ & $66.2 \%$ \\
\hline \multirow{2}{*}{ Non-Entrepreneurs } & $n$ & 810 & 1649 \\
\hline & $\%$ & $32.9 \%$ & $67.1 \%$ \\
\hline
\end{tabular}

\section{Table 2. Cross Column Table of Entrepreneurshipx Reasons for Not Participating in Continuing Education.}

\begin{tabular}{|c|c|c|c|c|}
\hline \multirow[b]{2}{*}{ Reasons for not Participating } & \multicolumn{4}{|c|}{ Counts } \\
\hline & Entrepreneurs & $\begin{array}{l}\text { Non- } \\
\text { Entrepreneurs }\end{array}$ & Total & $\begin{array}{l}\text { Adjusted } \\
\text { Residuals }\end{array}$ \\
\hline Work restrictions & 150 & 11 & 161 & .8 \\
\hline Economic considerations & 17 & 0 & 17 & 1.3 \\
\hline Lack of time & 792 & 92 & 884 & $2.7^{*}$ \\
\hline $\begin{array}{l}\text { Family responsibilities are too } \\
\text { heavy }\end{array}$ & 117 & 6 & 123 & 1.5 \\
\hline Traffic inconvenience & 13 & 3 & 16 & 1.5 \\
\hline Disqualification & 3 & 0 & 3 & .5 \\
\hline Required courses are not provide & d52 & 11 & 63 & $2.6^{*}$ \\
\hline Improper course time & 20 & 4 & 24 & 1.4 \\
\hline Don't know course information & 143 & 7 & 150 & 1.8 \\
\hline Health factors & 19 & 0 & 19 & 1.3 \\
\hline Not interested in learning & 315 & 21 & 336 & 1.7 \\
\hline Lack of confidence in learning & 8 & 0 & 8 & .9 \\
\hline Total count & 1,649 & 155 & 1,804 & \\
\hline
\end{tabular}


Table 3. Summary of t-tests for Factors Influencing Intent to Enroll in Continuing Education.

\begin{tabular}{lllll} 
& Mean $(S D)$ & $t$ & $p$ & $\begin{array}{c}\text { Effect } \\
\text { Size }(\boldsymbol{d})\end{array}$ \\
\hline $\begin{array}{l}\text { Entrepreneurs } \\
(\mathrm{N}=194)\end{array}$ & $\begin{array}{l}\text { Non- } \\
\text { Entrepreneurs } \\
(\mathrm{N}=2,050)\end{array}$ & & & \\
\hline $1.62(0.68)$ & $1.64(0.65)$ & -0.33 & 0.74 & 0.03 \\
\hline $2.40(1.08)$ & $2.37(1.03)$ & 0.48 & 0.63 & 0.03 \\
\hline $2.02(1.01)$ & $1.90(0.84)$ & 1.75 & 0.08 & 0.14 \\
\hline $1.97(0.85)$ & $1.87(0.81)$ & 1.66 & 0.09 & 0.12 \\
\hline $1.96(0.86)$ & $1.90(0.85)$ & 0.88 & 0.38 & 0.07 \\
\hline $2.27(1.07)$ & $2.07(0.97)$ & 2.76 & $0.04^{*}$ & 0.20 \\
\hline $2.40(1.06)$ & $2.16(0.99)$ & 3.29 & $0.01^{*}$ & 0.24 \\
\hline $3.28(1.08)$ & $3.25(1.14)$ & 0.38 & 0.71 & 0.00
\end{tabular}

Notes: The higher the value, the less significant it is. According to Cohen (1998), the effect size for independent $t$-tests adopt the $d$ statistic with values below 0.2 indicates a small effect size.

benchmark, as well as providing some generalizable results for other nations and cultures.

The first finding is that only $8 \%$ of Taiwan's youth reported self-employment. While within the range of reported youth self-employment in Europe, but the range was from $4.3 \%$ to $11.1 \%$ in Germany (Ortlieb et al., 2017). Based on z-score analysis, Taiwan's youth entrepreneurship was higher than the average rate for upper-middle income countries, including Japan (Niiyama et al., 2018), while lower that the average rate for lower-income countries, including China (Wang et al., 2016). Similarly, youth in Taiwan tend to not take the initiative towards pursuing continuing education, with far less participation than OECD countries and other developed Asian countries, such as Japan and Korea (OECD, 2018). We speculate that these phenomena reflect the blended nature of Taiwan's academic culture, positioned between traditional Chinese culture and Western culture. Thus while, Chinese culture, based on credentialism, tends to hold traditional academic higher education as a virtue at the expense of advocating youth independence and self-employment. Credentialism also places lower value on continuing education. This fits with the findings of Thomas (2009) who argues that academic pressure is a major factor hindering young entrepreneurs' willingness to start a business. On the other hand, Western aspects of Taiwan's educational culture emphasize individualism, which encourages entrepreneurship (Wang, \& Millington, 2011). Therefore, even though the Taiwan government strongly advocates and rewards youth entrepreneurship and promotes continuing education (Ministry of Education, 2009, 2010), full implementation of policy has yet to yield strong results. 
Based on our findings, continuing education is not associated with youth entrepreneurship. That is, enrollment or non-enrollment in continuing education demonstrated no relationship with youth entrepreneurship. This result is surprising, but may be due to the insufficiency of current continuing education programs in attracting, retaining, and inspiring learners to engage in entrepreneurship. Thus, in order to evaluate this finding, respondents' reasons for not taking continuing education were evaluated for entrepreneurial and non-entrepreneurial Taiwanese youth. Specifically, young entrepreneurs were reluctant to take continuing education due to two reasons: "lack of time" and "not providing the required courses". This can be explained by the fact that entrepreneurs often less free time (Kollmann et al., 2019) and may choose not to continue their studies as a result.

However, the primary reason for their decision not to take continuing education courses is due to the reality that many neither official nor private continuing education institutions in Taiwan are currently providing the courses considered important for young entrepreneurs. This finding is potentially linked to the fact that entrepreneurs tend to be more autonomous and, as such, make responsible life decisions (Ortlieb et al., 2017). For entrepreneurship education, it is crucial to provide appropriate curriculum content which is research based (Bhat \& Khan, 2014) and is integrated and includes hands-on activities (Karimi et al., 2010). This corresponds to the recommendations of Yang, et al. (2019), who claim that the main reason why entrepreneurship education in universities fails in its expected role is that the curriculum is more theoretical than practical. Furthermore, by analyzing the factors influencing the willingness of youth to participate in continuing education in the future, young entrepreneurs are less concerned with tuition fees and transportation issues than non-entrepreneurs. This might suggest that, if the course content fitted entrepreneurs' needs, factors such as tuition fees and commuting time would not affect their perception of the value of the program and resulting willingness to enroll.

\section{Conclusions and Limitations}

This study utilized AEST 2015 data collected by the government, with good reliability and validity. However, the data is based on interviews that may have been conducted up to five years and, thus, may not adequately reflect the current situation in Taiwan. Nevertheless, the results are a contribution, insofar as they demonstrate, with empirical data, the lack of correspondence between continuing education and entrepreneurship for youth, and the importance of factors such as time, course content, and classes fitting learners' needs, and the relative lack of importance based on tuition and travel expenses, for entrepreneurial youth.

Continuing education units must adapt to meet the challenges of increased competition, decreased funding, and widespread changes in educational delivery methods by fostering increased entrepreneurial activities (Downey, et al., 2006). However, according to our secondary analysis of AEST 2015 data, there is no strong relationship between continuing education and youth entrepreneurship in Taiwan. We suggest that educational reforms continue (MOE, 2010), according to the suggestions of scholars in 
the area of youth entrepreneurship and continuing education, such as providing more practical experiences, and offering courses that will meet the needs of potential entrepreneurs (Afolabi, et al., 2017; Bao, et al., 2018; Cardoso, et al., 2018).

Furthermore, this study demonstrated that youth entrepreneurship in Taiwan is higher than more developed countries, but lower than developing countries, as well as mainland China. While this might be due to Taiwan's unique culture educational culture blending Eastern and Western values, it should be noted that the majority of selfemployment in developing countries, as well as China, are family-based, agricultural, temporary, or non-contractual (International Labour Office, 2017). Self-employment is also associated with several negative outcomes, such as stress and insomnia (Kollmann et al., 2019) and insecurity and instability (Nazio \& Gábos, 2017). As such, both the value and assessment of entrepreneurship should be further evaluated and other potential proxy variables explored in future studies.

\section{References}

Ács, Z.J., Szerb, L., Lafuente, E., \& Lloyd, A. (2018). What can we do to improve the entrepreneurial ecosystem? In Global Entrepreneurship and Development Index 2018, (pp:55-63). Cham: Springer.

Afolabi, M.O., Kareem, F.A., Okubanjo, I.O., Ogunbanjo, O.A., \& Aninkan, O.O. (2017). Effect of entrepreneurship education on selfemployment initiatives among Nigerian science and technology students. J Edu Prac, 8(15), 44-51.

Arend, R.J. (2019). Entrepreneurial entrepreneurship youth education: Initiating grounded theory. Entrepre Edu, 2(1-2), 71-89.

Bao, Z., Teng, H., Peng, J., \& Liu, X. (2018). The influencing factors and improvements of college students' abilities in innovation and entrepreneurship-from the perspective of school and society. In 2018 8th International Conference on SSER. Paris: Atlantis Press.

Bates, T., \& Bates, T.M. (1997). Race, selfemployment, and upward mobility: An illusive American dream. Washington D.C.: Woodrow Wilson Center Press.
Bhat, S., \& Khan, R. (2014). Entrepreneurship education ecosystem: An assessment study of J\&K state. Inter J Econ, Commer Manag, 2(4), 1-8.

Cardoso, A., Cairrão, À., Petrova, D., \& Figueiredo, J. (2018). Assessment of the effectiveness of the entrepreneurship classes in the Bulgarian secondary education. J Entrepr Edu, 21(2), 1-21.

Chen, S.C., Hsiao, H.C., Chang, J.C., Chou, C.M., Chen, C.P., \& Shen, C.H. (2015). Can the entrepreneurship course improve the entrepreneurial intentions of students? Inter Entrepr Manag J, 11(3), 557-569.

Chowdhury, F., Audretsch, D.B., \& Belitski, M. (2019). Institutions and entrepreneurship quality. Entrepr Theo Prac, 43(1), 51-81.

Cohen, J. (1988). Statistical power analysis for the behavioral sciences. New Jersey: Lawrence Erlbaum.

Ding, X.Q., \& Yan, J.R. (2011). Discussion on the relationship model of factors affecting the employment ability of college students: Take the general university in Taiwan as an example. Edu Polic Forum, 14(2), 1-33. 
Downey, J.A., Pusser, B., \& Turner, J.K. (2006). Competing missions: balancing entrepreneurialism with community responsiveness in community college continuing education divisions. New Direc Comm Coll, 136, 7582.

Feng, J.Y. (2016). Building a thriving ecosystem for young entrepreneurs in Taiwan. Innova: Tech, Govern, Global, 11(1-2), 4-11.

Hsu, C.Y., \& Wang, S.M. (2019). Social entrepreneurial intentions and its influential factors: A comparison of students in Taiwan and Hong Kong. Innova Edu Teach Inter, 56(3), 385-395.

International Labour Office. (2017). Global Employment Trends for Youth 2017: Paths to a better working future. Geneva: International Labour Office.

Jia, L., Yuanyuan, G., \& Cong, C. (2018). Entrepreneurship effectiveness: A metaanalysis on entrepreneurs. Foreign Eco Manag, 40(6), 29-43.

Jin, P. (2008). Talking about the lifelong development trend of adult continuing education in China. Chin Adult Edu, 8, 25-26.

Karimi, S., Chizari, M., Biemans, H.J., \& Mulder, M. (2010). Entrepreneurship education in Iranian higher education: The current state and challenges. Euro J Sci Res, 48(1), $35-50$

Kollmann, T., Stöckmann, C., \& Kensbock, J.M. (2019). I can't get no sleep-The differential impact of entrepreneurial stressors on workhome interference and insomnia among experienced versus novice entrepreneurs. J Bus Ventu, 34(4), 692-708.

Liao, L.X. (2013). An analysis of the implementation of entrepreneurship education in higher education institutions in Japan and Taiwan. Manag Infor Compu, 2(1), 157-163.

Liberto, V.N. (2005). Entrepreneurship in continuing dental education: A dental school perspective. J Am Coll Dentists, 72(2), 1011.

Lim, D.H., You, J., Kim, J., \& Hwang, J. (2019). Instructional design for adult and continuing higher education: Theoretical and practical considerations. In Y. Vovides \& L.R. Lemus (Eds.). Optimizing instructional design methods in higher education (pp. 73-100). Hershey, PA: IGI Global.
Liu, P. (2018). Research on the path of university innovation transformation-Based on the case of Nanyang Technological University in Singapore. China High Edu, 601(Z1), 79-81.

Liu, R.L., \& Lin, D.S. (2011). A Study on the factors influencing graduation flow of college students. Contemp Edu Res, 19(1), 101144.

Lu, H.K., Chang, K.C., Yan, M.J., \& Lin, P.C. (2016). Organizational innovation for continuing education in higher education in Taiwan: The case of the Chinese Culture University. Inter J Contin Edu Lifel Learn, $8(2), 128$.

Ministry of Education. (2009). U-Start innovation and entrepreneurship program. Retrieved from https://ustart.yda.gov.tw/files/40-1000-1825.php?Lang=zh-tw.

Ministry of Education. (2010). Excellent: The way to be outstanding - Technical and Vocational Education in Taiwan. Taipei: Ministry of Education.

Ministry of Education. (2018). 2015 Adult Education Survey in Taiwan (AI010003) [data file]. Survey Research Data Archive, Academia Sinica.

Nazio, T., \& Gábos, A. (2017). Policy themes on family matters. In J. O'Reilly, M. Clémentine, T, Nazio, \& M. Smith (Eds.), Youth employment: STYLE handbook (pp. 229-231). Mountain View, CA: CHROME.

Nikolova, M. (2019). Switching to selfemployment can be good for your health. J Bus Ventu, 34(4), 664-691.

Niiyama, H., Kontkanen, I., Paavilainen, E., \& Kamibeppu, K. (2018). A comparison of personality maturity among Japanese youth and Finnish young adult students: a crosssectional study using Erikson psychosocial stage inventory and sense of coherence scale. Inter J Adole Youth, 23(4), 482-495.

Organisation for Economic Co-operation and Development. (2010). Education at a glance 2010: OECD indicators. Paris: OECD.

Organisation for Economic Co-operation and Development. (2018). Education at a glance 2018: OECD indicators. Paris: OECD.

Ortlieb, R., Sheehan, M., \& Masso, J. (2017). Is self-employment a solution to young peo- 
ple's employment problems? In J. O'Reilly, M. Clémentine, T, Nazio, \& M. Smith (Eds.), Youth employment: STYLE handbook (pp. 229-231). Mountain View, CA: CHROME.

Quadrini, V. (1999). The importance of entrepreneurship for wealth concentration and mobility. Rev Inco Wealth, 45(1), 1-19.

Pantea, M. C. (2016). On entrepreneurial education: Dilemmas and tensions in nonformal learning. Stud Contin Edu, 38(1), 86-100.

Rapp, C., Shore, J., \& Tosun, J. (2018). Not so risky business? How social policies shape the perceived feasibility of self-employment. J Eur Soc Policy, 28(2), 143-160.

State Council of the People's Republic of China. (2015). Implementation opinions on deepening the reform of innovation and entrepreneurship education in colleges and universities. Retrieved from http://www.gov.cn/xinwen/201505/13/content_2861327.htm.

Sun, T.Y., \& Huang, T.C. (2018). The reconstruction of positive multicultural environments through translingualism in Taiwan. Psychol, 8(5), 192-203.

Thomas, M.K. (2009). The impact of education histories on the decision to become selfemployed: A study of young, aspiring, minority business owners. Small Bus Eco, 33(4), 455.

Wada, B.T., \& Muhammad, I.N. (2010). Adult education, entrepreneurship and poverty al- leviation among Kano housewives. Bayero J Interdisc Stud, 1(2), 94 - 102.

Wang, J., Bao, C., Cao, J., \& Kring, S. (2016). Jobs and skills for youth: Review of policies for youth employment of China. Geneva: International Labour Office.

Wang, C.Y., \& Hsu, W.C. (2016). Classroom climate, instrumental help-seeking behaviour, and learnerl among continuing education students. Merit Res J Edu Rev, 4(2), 19-27.

Wang, W., Lu, W., \& Millington, J.K. (2011). Determinants of entrepreneurial intention among college students in China and USA. J Global Entrepre Res, 1(1), 35-44.

Yang, J.C.C. (2019). The shaping of academic culture in higher education in Taiwan: Confucianism, historic legacy, and Western influences. In A. Jun \& C. S. Collins (Eds.), Higher education and belief systems in the Asia Pacific region (pp. 15-25). Springer, Singapore.

Yang, M.N., Wang, H., Wang, C.M., Chen, H.M., \& Cai, W. (2019). On the integration of innovation and entrepreneurship education of college students and basic courses of materials major. Edu Teach Forum, 407e, 99-101.

Yu, M.C., Goh, M., Kao, H.Y., \& Wu, W.H. (2017). A comparative study of entrepreneurship education between Singapore and Taiwan. Manag Dec, 55(7), 1426-1440. 